\title{
Plasma Phospholipid Long-Chain n-3 Polyunsaturated Fatty Acids and Body Weight Change
}

\author{
Marianne U. Jakobsen ${ }^{1,2,3}$ Claus Dethlefsen ${ }^{2} \quad$ Karen M. Due $^{2} \quad$ Nadia Slimani $^{4}$ \\ Veronique Chajès ${ }^{4}$ Anne M. May,6 Thorkild I.A. Sørensen ${ }^{7} \quad$ Jytte Halkjær $^{8}$ \\ Anne Tjønneland ${ }^{8}$ Francoise Clavel-Chapelon ${ }^{9,10}$ Marie-Christine Boutron-Ruault ${ }^{9,10}$ \\ Guy Fagherazzi ${ }^{9,10}$ Birgit Teucher ${ }^{11}$ Rudolf Kaaks ${ }^{11}$ Heiner Boeing ${ }^{12}$ Madlen Schütze ${ }^{12}$ \\ Antonia Trichopoulou ${ }^{13,14}$ Dimosthenis Zylis ${ }^{13,14}$ George Makrygiannis ${ }^{14}$ Domenico Palli ${ }^{15}$ \\ Amalia Mattiello ${ }^{16}$ Giovanna Tagliabue ${ }^{17}$ Daphne L. van der A ${ }^{6}$ H.B. Bueno-de-Mesquita ${ }^{6,18}$ \\ Laudina Rodríguez ${ }^{19}$ Noémie Travier ${ }^{20}$ Esther Molina-Montes ${ }^{21,22}$ José M. Huerta ${ }^{22,23}$ \\ Aurelio Barricarte ${ }^{22,24}$ Pilar Amiano ${ }^{22,25}$ Jonas Manjer ${ }^{26} \quad$ Elisabet Wirfält ${ }^{27}$ \\ Ingegerd Johansson ${ }^{28}$ Göran Hallmans ${ }^{29}$ Kay-Tee Khaw $^{30}$ Nicholas J. Wareham ${ }^{31}$ \\ Francesca Crowe ${ }^{32}$ Isabelle Romieu ${ }^{4}$ Elio Riboli ${ }^{33}$ Petra H.M. Peeters ${ }^{5,33}$ Kim Overvad ${ }^{2,3}$
}

${ }^{1}$ Department of Clinical Epidemiology, ${ }^{2}$ Department of Cardiology, Center for Cardiovascular Research, Aalborg Hospital, Aarhus University Hospital, Aalborg, ${ }^{3}$ Department of Epidemiology, School of Public Health, Aarhus University, Aarhus, Denmark, ${ }^{4}$ Nutrition and Metabolism, International Agency for Research on Cancer, Lyon, France, ${ }^{5}$ Julius Centre for Health Sciences and Primary Care, University Medical Centre Utrecht, Utrecht, ${ }^{6}$ National Institute for Public Health and the Environment (RIVM), Bilthoven, The Netherlands, ${ }^{7}$ Institute of Preventive Medicine, Copenhagen University Hospital, ${ }^{8}$ The Danish Cancer Society, Institute of Cancer Epidemiology, Copenhagen, Denmark, ${ }^{9}$ Inserm, Centre for Research in Epidemiology and Population Health, U1018, Institut Gustave Roussy, ${ }^{10}$ Paris South University, UMRS 1018, Villejuif, France, ${ }^{11}$ German Cancer Research Center, Department of Cancer Epidemiology, Heidelberg, ${ }^{12}$ Department of Epidemiology, German Institute of Human Nutrition, Potsdam-Rehbruecke, Nuthetal, Germany, ${ }^{13}$ WHO Collaborating Center for Food and Nutrition Policies, Department of Hygiene, Epidemiology and Medical Statistics, University of Athens Medical School, ${ }^{14} \mathrm{Hellenic} \mathrm{Health}$ Foundation, Athens, Greece, ${ }^{15}$ Molecular and Nutritional Epidemiology Unit, Cancer Research and Prevention Institute, ISPO, Florence, ${ }^{16}$ Department of Clinical and Experimental Medicine, Federico II University, Naples, ${ }^{17}$ Cancer Registry and Environmental Epidemiology Division, National Cancer Institute, Milan, Italy, ${ }^{18}$ Department of Gastroenterology and Hepatology, University Medical Centre Utrecht (UMCU), Utrecht, The Netherlands, ${ }^{19}$ Public Health and Participation Directorate, Health and Health Care Services Council, Asturias, ${ }^{20}$ Unit of Nutrition, Environment and Cancer, Catalan Institute of Oncology, IDIBELL, Barcelona, ${ }^{21}$ Andalusian School of Public Health, Granada, ${ }^{22}$ CIBER Epidemiología y Salud Pública (CIBERESP), Barcelona, ${ }^{23}$ Department of Epidemiology, Murcia Regional Health Council, Murcia, ${ }^{24}$ Public Health Institute of Navarra, Pamplona, ${ }^{25}$ Public Health Division of Gipuzkoa, Basque Government, Spain, ${ }^{26}$ Department of Surgery, Skåne University Hospital Malmö, Lund University, ${ }^{27}$ Department of Clinical Sciences in Malmö/Nutrition Epidemiology, Lund University, Malmö, ${ }^{28}$ Department of Odontology, Umeå University, ${ }^{29}$ Department of Public Health and Clinical Medicine, Umeå University, Nutritional Research, Umeå, Sweden, ${ }^{30}$ Clinical Gerontology Unit, Department of Public Health and Primary Care, Institute of Public Health, University of Cambridge, ${ }^{31}$ MRC Epidemiology Unit, Institute of Metabolic Science, Addenbrooke's Hospital, Cambridge, ${ }^{32}$ Cancer Epidemiology Unit, Nuffield Department of Clinical Medicine, University of Oxford, Oxford, ${ }^{33}$ Department of Epidemiology and Biostatistics, School of Public Health, Imperial College London, London, UK

\section{Keywords}

Body weight . Cohort study · n-3 fatty acids .

Omega-3 fatty acids $\cdot$ Weight change

\section{Summary}

Objective: We investigated the association between the proportion of long-chain n-3 polyunsaturated fatty acids (PUFA) in plasma phospholipids from blood samples drawn at enrollment and subsequent change in body weight. Sex, age, and BMI were considered as potential effect modifiers. Method: A total of 1,998 women and men participating in the European Prospective Investigation into Cancer and Nutrition (EPIC) were followed for a median of 4.9 years. The associations between the proportion of plasma phospholipid long-chain n-3 PUFA and change in weight were investigated using mixed-effect linear regression. Results: The proportion of long-chain n-3 PUFA was not associated with change in weight. Among all participants, the 1-year weight change was $-0.7 \mathrm{~g}$ per $1 \%$ point higher long-chain $\mathrm{n}-3$ PUFA level (95\% confidence interval: -20.7 to 19.3). The results when stratified by sex, age, or BMI groups were not systematically different. Conclusion: The results of this study suggest that the proportion of long-chain n-3 PUFA in plasma phospholipids is not associated with subsequent change in body weight within the range of exposure in the general population.

\section{KARGER}

Fax +497614520714

Information@Karger.de

www.karger.com (c) 2011 S. Karger GmbH, Freiburg

1662-4025/11/0044-0312\$38.00/0

Accessible online at:

www.karger.com/ofa
Marianne Uhre Jakobsen

School of Public Health, Department of Epidemiology

Aarhus University

Bartholins Allé 2, 8000 Aarhus C, Denmark

Tel. +45 8-9426107, Fax -6131580

muj@soci.au.dk 


\section{Introduction}

Although obesity is known to be a disorder of energy balance, an understanding of its causes and treatment remains elusive. Studies in rodents show that adding the long-chain n-3 polyunsaturated fatty acids (PUFA), eicosapentaenoic acid (EPA, C20:5n-3) and docosahexaenoic acid (DHA, C22:6n-3), to a rodent diet reduces body fat mass and prevents development of obesity [1]. These beneficial effects of long-chain n-3 PUFA on body fat mass have been related to alterations of gene expression that increase fat oxidation and energy expenditure and reduce fat deposition [1].

Fish consumption is the major dietary source of long-chain n-3 PUFA. No epidemiological studies have investigated the association between fish consumption and body weight. One study, however, investigated the association between fish consumption and subsequent change in waist circumference [2]. In that study no substantial associations were found. Biologically, however, it may not be the dietary intake of long-chain n-3 PUFA that is the relevant exposure in studies of body weight and fat distribution but the endogenous exposure. The proportion of long-chain n-3 PUFA in plasma phospholipids is an objective measure of the endogenous exposure, reflecting habitual dietary intake of long-chain n-3 PUFA (weeks to months) and the fatty acid metabolism [3, 4]. In a case-control study by Karlsson et al. [5], the proportion of DHA, but not EPA, in plasma phospholipids was significantly lower in obese female adolescents compared with lean age-matched females. Among male adolescents, the proportion of DHA was also lower in obese compared with lean male adolescents, although not statistically significant; there was no difference in the proportions of EPA [5].

We investigated the association between the proportion of long-chain n-3 PUFA in plasma phospholipids and subsequent change in body weight. Based on previous findings, we hypothesized that the level of plasma phospholipid longchain n-3 PUFA is inversely associated with change in body weight. We used data from the European Prospective Investigation into Cancer and Nutrition (EPIC). Sex, age, and BMI were considered as potential effect modifiers.

\section{Material and Methods}

\section{Study Population}

This study is a part of the Physical Activity, Nutrition, Alcohol, Cessation of Smoking, Eating out of Home and Obesity (PANACEA) project, which aims at studying determinants of body weight and subsequent changes in weight in Europe using data from the EPIC. The EPIC population includes 521,448 participants recruited in 23 centers located in 10 European countries: Denmark, France, Germany, Greece, Italy, The Netherlands, Norway, Spain, Sweden, and UK [6, 7]. At enrollment, which took place between 1992 and 2000, information on habitual diet, sociodemographic and lifestyle characteristics, and anthropometry was collected. Blood samples of $\geq 30 \mathrm{ml}$ were drawn and stored at $5-10{ }^{\circ} \mathrm{C}$ protected from light and transported to local laboratories for processing and aliquoting. The only exceptions were the Oxford center (UK), where blood samples were collected from a network of general practitioners and transported to a central laboratory by post, and the Danish and Swedish centers where blood samples were aliquoted within $1 \mathrm{~h}$ of drawing. The blood samples were aliquoted into $0.5 \mathrm{ml}$ plastic straws (plasma, serum, erythrocytes, and buffy coat for DNA) and stored in liquid nitrogen at $-196^{\circ} \mathrm{C}$. The only exceptions were the Danish and Swedish centers where samples were aliquoted into tubes and stored in nitrogen vapor at $-150{ }^{\circ} \mathrm{C}$ and in freezers at $-70{ }^{\circ} \mathrm{C}$, respectively. Follow-up information on anthropometry was collected $2.7-9.9$ years ( $80 \%$ central range) after initial enrollment.

To study proportions of fatty acids in plasma phospholipids and associations with dietary intakes, 16 geographical regions were designated by grouping some of the 23 centers: Aarhus and Copenhagen (Denmark); northeast France; Heidelberg (southwest Germany); Potsdam (east Germany); Greece; Florence (central Italy); Naples and Ragusa (southern Italy); Turin and Varese (northern Italy); Bilthoven and Utrecht (The Netherlands); Asturias, Navarre, and San Sebastian (northern Spain); Granada (southern Spain); Murcia (southeastern Spain); Malmö (southern Sweden); Umeå (northern Sweden); Cambridge (UK); and Oxford (UK) [8]. Except for France, where only women were enrolled, 100 women and 100 men from each of the 16 regions were randomly selected to participate in the biomarker study, which resulted in a total of 3,100 persons. Selection was stratified by four age groups $(45-49,50-54$, 55-59, and 60-64 years) with an equal number of women and men in each group. As far as possible, equal numbers of persons were selected for each season in which the blood samples were collected. Only persons for whom information on dietary intake was obtained were included ( $\mathrm{n}=3,089)$. Laboratory results for plasma phospholipid analyses were available for 3,009 persons. No data for Norway are included in the study as Norway joined the EPIC after selection of participants for the biomarker study.

The exclusion criteria for this study were length of follow-up equals to 0 , extreme reported energy intake $(<1 \%$ and $>99 \%$ percentile of the ratio of reported energy intake to estimated energy requirement), missing information on weight or height, extreme anthropometric measurements (height $<130 \mathrm{~cm}, \mathrm{BMI}<16 \mathrm{~kg} / \mathrm{m}^{2}$, waist circumference $<40$ or $>160 \mathrm{~cm}$, waist circumference $<60 \mathrm{~cm}$ if $\mathrm{BMI}>25 \mathrm{~kg} / \mathrm{m}^{2}$, or average weight change $>5 \mathrm{~kg}$ /year during the observation period), missing information on lifestyle (tobacco or alcohol consumption), pregnancy, and chronic disease (prevalent diabetes, cancer, or cardiovascular disease) at enrollment. The final population consisted of 1,998 persons (54\% women).

\section{Plasma Phospholipid Analyses}

Samples of the same sex and age category were ordered randomly within analysis batches. Each batch included one sample from each participating center and one sample from a standard pool for quality control (injected twice at the middle and end of each series). Fatty acid composition in plasma phospholipids was analyzed as described by Saadatian-Elahi et al. [8]. Briefly, phospholipids were purified by adsorption chromatography on silica tubes and trans-methylated at room temperature. The percentage composition of 22 individual fatty acids with a chain length between 14 and 22 carbons was determined by gas chromatography (a 30-meter capillary column, i.d. $0.32 \mathrm{~mm}$ ) with helium as a carrier gas. Analytic quality control was carried out by the daily use of the standard quality control plasma $(n=137)$ and by analyzing the fatty acid composition of 10 aliquots of the standard quality control plasma during the same day. The between-day coefficient of variation $(\mathrm{CV})$ was $3.86 \%$ for EPA, $4.70 \%$ for docosapentaenoic acid (DPA, C22:5n-3), and 4.55\% for DHA. The within-day CV was $4.18 \%$ for EPA, 3.05\% for DPA, and 1.36\% for DHA. For this study we used the proportion of total long-chain n-3 PUFA defined as the sum of the proportions of EPA, DPA and DHA, and the proportions of the individual long-chain n-3 PUFA. 
Data on Anthropometry and Lifestyle Factors

At enrollment, height and weight were measured by trained staff by standardized methods in all centers, except in the French and Oxford (UK) centers where information on anthropometry was collected through standardized questionnaires [9]. Height and weight were measured without shoes. Height was measured to the nearest $0.1,0.5$, or $1.0 \mathrm{~cm}$, and weight was measured to the nearest 0.1 or $0.5 \mathrm{~kg}$ depending on center [9]. Weight was adjusted to reduce heterogeneity due to protocol differences in clothing worn during measurement (light underwear, light clothing, or normal clothing). For participants in light clothing the adjustment was $-1.0 \mathrm{~kg}$ and for participants in normal clothing $-1.5 \mathrm{~kg}[9,10]$. In the Oxford center, self-reported values were corrected using prediction equations [11]

At follow-up, information on weight was collected through standardized questionnaires in all centers, except in the Bilthoven (The Netherlands) and Cambridge (UK) centers. In the Bilthoven center, weight was measured by trained staff for 57 persons (Doetinchem), and self-reported values were collected from 56 persons (Amsterdam/Maastricht). In the Cambridge center, weight was measured by trained staff as previously described [12]. Weight was adjusted to reduce heterogeneity due to protocol differences in clothing worn during measurement as described above. No follow-up data were available from Ragusa and Turin centers in Italy. The outcome measure was defined as weight at follow-up minus weight at enrollment and expressed as average 1-year change in weight. BMI was calculated as weight in kilograms divided by height in meters squared.

Information on sociodemographic (sex, age, menopausal status, and highest educational level achieved) and lifestyle (tobacco consumption and physical activity) characteristics was collected through standardized questionnaires at enrollment. A four-level physical activity index (inactive, moderately inactive, moderately active, and active) was derived by combining occupational and leisure time physical activity over the past year [13]

\section{Statistical Analyses}

Median and $80 \%$ central range for age, BMI, and proportions of plasma phospholipid long-chain n-3 PUFA at enrollment and annual weight change were calculated.

The associations between the proportion of plasma phospholipid longchain n-3 PUFA (\%) and 1-year change in weight $(\mathrm{g})$ were investigated using mixed-effect linear regression with random effects on intercept taking into account the clustering of the data within geographical regions nested within countries. Exposure and outcome variables were modeled as continuous variables. Analyses were carried out among all participants and separately for women and men.

Two models were used. Model 1 included country, geographical region, and the proportion of plasma phospholipid long-chain n-3 PUFA. EPA, DPA, and DHA were analyzed in mutually adjusted models. Model 2 equals model 1 plus adjusting for suggested risk factors of development of obesity: sex (all participants only), age, BMI at enrollment, menopausal status (pre-, peri-, and post-menopausal, women only), highest educational level achieved (none, primary school, technical or professional school, other secondary school, university or higher education, and not specified), smoking status (never, former, current, and unknown), and physical activity level (inactive, moderately inactive, moderately active, and active). Adjustment of continuous variables was done using restricted cubic spline regression. For categorical variables, missing values were treated as a separate category. By stratifying the data, possible effect modification by sex, age (classified as age at enrollment of $<60$ and $\geq 60$ years), and BMI (classified as BMI at enrollment of 18.5 to $<25 \mathrm{~kg} / \mathrm{m}^{2}, 25$ to $<30 \mathrm{~kg} / \mathrm{m}^{2}$, and $\geq 30 \mathrm{~kg} / \mathrm{m}^{2}$ ) was investigated. We tested the associations for the proportions of long-chain n-3 PUFA for non-linearity in restricted cubic spline regression models. No violations were detected. In addition, we used categorical analysis to investigate the association between the proportion of plasma phospholipid long-chain n-3 PUFA and subsequent weight change comparing the highest versus the lowest quintile of exposures to maximize the exposure contrast.

Data analyses were performed using Stata statistical software, release 10.1 (Stata Corporation, College Station, TX, USA)

\section{Results}

Characteristics of the study population are shown in table 1 . The median age was 54 years (80\% central range: 47-62 years) among women and 54 years (80\% central range: $47-62$ years) among men; the median BMI was $25 \mathrm{~kg} / \mathrm{m}^{2}$ (80\% central range: $\left.21-32 \mathrm{~kg} / \mathrm{m}^{2}\right)$ among women and $26 \mathrm{~kg} / \mathrm{m}^{2}(80 \%$ central range: $23-31 \mathrm{~kg} / \mathrm{m}^{2}$ ) among men. The median proportion of total plasma phospholipid long-chain n-3 PUFA was $7.5 \%(80 \%$ central range: $5.1-11.0 \%)$ among women and $7.1 \%$ (80\% central range $4.6-10.3 \%)$ among men. The median follow-up time was 5.0 years $(80 \%$ central range: $2.5-9.9$ years) among women and 4.9 years $(80 \%$ central range: $2.7-$ 9.9 years) among men, and the median annual weight change was $87 \mathrm{~g}$ (80\% central range: $-1,077$ to $1,115 \mathrm{~g})$ among women and $62 \mathrm{~g}$ (80\% central range: $-1,072$ to $1,153 \mathrm{~g})$ among men.

Table 2 shows the associations between the proportions of plasma phospholipid long-chain n-3 PUFA and subsequent changes in weight among all participants and separately among women and men. Neither the proportion of total longchain n-3 PUFA nor the proportions of EPA, DPA, or DHA were consistently or significantly associated with changes in weight. Among all participants, the annual weight change was $-0.7 \mathrm{~g}$ per $1 \%$ point higher total long-chain $\mathrm{n}-3$ PUFA level (95\% confidence interval (CI): -20.7 to $19.3 \mathrm{~g}$ ), $-22.7 \mathrm{~g}$ per $1 \%$ point higher EPA level (95\% CI: -85.1 to $39.8 \mathrm{~g}$ ), $16.8 \mathrm{~g}$ per $1 \%$ point higher DPA level (95\% CI: -200.4 to $233.9 \mathrm{~g}$ ), and $10.5 \mathrm{~g}$ per $1 \%$ point higher DHA level (95\% CI: -28.6 to $49.6 \mathrm{~g}$ ). The results when stratified by sex were not systematically different; neither were the results when stratified by age (online supplementary table 1, available at http://content. karger.com/ProdukteDB/produkte.asp?doi=330710) or by BMI (online supplementary table 2, available at http://content. karger.com/ProdukteDB/produkte.asp?doi=330710). Also in the categorical analyses comparing the weight change among persons in the highest versus the lowest quintile of exposure, no systematic or significant differences were found (data not shown).

\section{Discussion}

In this study, the proportion of long-chain n-3 PUFA in plasma phospholipids was not associated with subsequent change in body weight among women and men participating in the EPIC.

Exclusions were primarily due to non-response at followup. Non-response may be related to either the exposure to long-chain n-3 PUFA or to the change in weight but most 


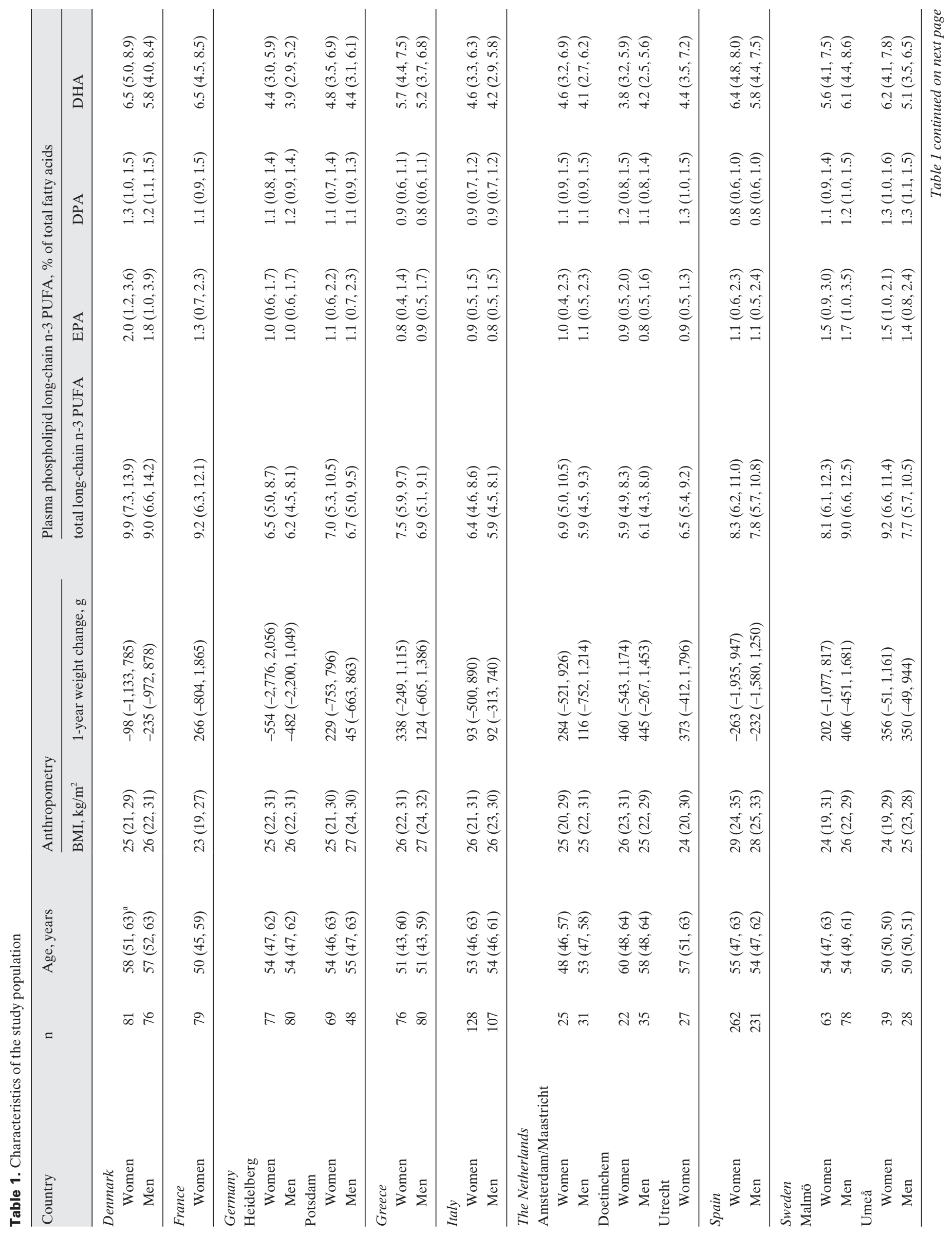


likely not to both the exposure to long-chain n-3 PUFA and the change in weight. Thus, selection bias is unlikely to have affected the results. The proportion of long-chain n-3 PUFA in plasma phospholipids is an objective long-term measure of the endogenous exposure, and using data from different populations with different diets allowed us to investigate the association between the proportion of long-chain n-3 PUFA in plasma phospholipids and subsequent change in body weight over a wide range of exposures. At enrollment, weight was measured by trained staff, but at follow-up information on weight was self-reported. However, most likely the reporting of follow-up weight was not related to the exposure to long-chain n-3 PUFA. Thus, in this study information bias is of limited concern. Relevant control for potential confounders did not change the observed associations. Residual confounding is therefore unlikely. However, confounding from other risk factors of development of obesity not taken into account remains a possible explanation for the observed associations. The proportion of long-chain $n-3$ PUFA in plasma phospholipid level reflects habitual dietary intake and endogenous fatty acid metabolism. We decided not to control for potential confounding from diet as the measures of associations from models including diet would be without clear interpretation.

The principal long-chain n-3 PUFA in the diet are EPA and DHA with fish consumption being the main source. In addition to intake of long-chain n-3 PUFA, EPA can also be synthesized by humans from $\alpha$-linolenic acid (C18:3n-3) but conversion of $\alpha$-linolenic acid to EPA appears to be limited [14]. Studies in rodents show that adding long-chain n-3 PUFA to a rodent diet reduces body fat mass and prevents development of obesity [1]. These beneficial effects of longchain n-3 PUFA on body fat mass have been related to alterations of gene expression that increase fat oxidation and energy expenditure and reduce fat deposition [1]. The lack of an association between the proportion of long-chain $n-3$ PUFA in plasma phospholipids and body weight in this study is in contrast to previous findings. In a case-control study including 10 obese adolescents and 15 lean agedmatched controls, the proportion of DHA, but not EPA, in plasma phospholipids was significantly lower in obese females compared with lean females [5]. Among males, the proportion of DHA was also lower in obese compared with lean males, although not statistically significant; there was no difference in the proportions of EPA [5]. In a cross-sectional study including 60 normal-weight and 45 overweight adolescents the proportion of plasma DHA, but not EPA, was significantly lower among overweight adolescents as compared with normal-weight adolescents [15]. In another cross-sectional study the proportions of plasma EPA and DHA were significantly inversely associated with BMI and waist circumference among obese adults, but not among normal-weight or overweight adults [16]. However, the interpretation of the findings from that study is not clear as 
Table 2. Association between the proportion of plasma phospholipid long-chain n-3 PUFA (\%) and 1-year change in weight (g)

\begin{tabular}{|c|c|c|c|c|c|c|}
\hline & \multicolumn{2}{|c|}{ All participants $g / \%$ point } & \multicolumn{2}{|c|}{ Women $\mathrm{g} / \%$ point } & \multicolumn{2}{|c|}{ Men $g / \%$ point } \\
\hline & $\beta$ & $(95 \% \mathrm{CI})$ & $\beta$ & $(95 \% \mathrm{CI})$ & $\beta$ & $(95 \% \mathrm{CI})$ \\
\hline \multicolumn{7}{|c|}{ Total long-chain n-3 PUFA ${ }^{a}$} \\
\hline Model $1^{b}$ & -0.2 & $(-20.6,20.1)$ & 9.9 & $(-17.2,37.0)$ & -18.4 & $(-48.8,12.0)$ \\
\hline Model $2^{c}$ & -0.7 & $(-20.7,19.3)$ & 6.1 & $(-19.9,32.1)$ & -19.9 & $(-49.4,9.6)$ \\
\hline \multicolumn{7}{|l|}{$\mathrm{EPA}^{a}$} \\
\hline Model $1^{b}$ & -21.2 & $(-85.0,42.7)$ & 8.9 & $(-76.3,94.0)$ & -63.4 & $(-161.6,34.8)$ \\
\hline Model $2^{c}$ & -22.7 & $(-85.1,39.8)$ & 8.3 & $(-74.4,91.0)$ & -66.3 & $(-161.4,28.7)$ \\
\hline \multicolumn{7}{|l|}{$\mathrm{DPA}^{a}$} \\
\hline Model $1^{b}$ & 71.0 & $(-151.0,293.0)$ & -31.4 & $(-337.7,274.9)$ & 249.9 & $(-61.2,561.0)$ \\
\hline Model $2^{c}$ & 16.8 & $(-200.4,233.9)$ & -45.7 & $(-344.7,253.3)$ & 83.6 & $(-220.2,387.3)$ \\
\hline \multicolumn{7}{|l|}{$\mathrm{DHA}^{a}$} \\
\hline Model $1^{b}$ & 5.4 & $(-33.8,44.7)$ & 14.0 & $(-37.9,65.9)$ & -18.1 & $(-79.2,43.1)$ \\
\hline Model $2^{c}$ & 10.5 & $(-28.6,49.6)$ & 9.2 & $(-40.4,58.8)$ & -2.2 & $(-61.2,56.8)$ \\
\hline
\end{tabular}

${ }^{\mathrm{a}} \mathrm{n}=1,998$ for all participants; $\mathrm{n}=1,076$ for women; and $\mathrm{n}=922$ for men.

${ }^{b}$ From multilevel mixed-effect linear regression with random effects on intercept, taking into account the clustering of the data within geographical regions nested within countries. The proportions of the specific plasma phospholipid long-chain n-3 PUFA were analyzed in mutually adjusted models.

${ }^{\mathrm{c}}$ As model 1 plus adjusting for sex (all participants only), age, BMI at enrollment, menopausal status (women only), highest educational level achieved, smoking status, and physical activity level. analyses were stratified by BMI which was the outcome of the study.

The potential effects of intake of long-chain n-3 PUFA on body weight have been investigated in clinical trials. These studies, however, generally used combinations of EPA and DHA, which makes it difficult to discern specific effects and related health consequences of the individual long-chain n-3 PUFA. In addition, clinical trials used high pharmacologic doses of long-chain n-3 PUFA to ensure maximal therapeutic effects, but failed to provide information on potential threshold effects, particularly with respect to lower intakes compatible with median intakes in the general population which has been estimated to $0.57 \mathrm{~g} /$ day among women and $0.70 \mathrm{~g} /$ day among men [17]. In a trial of the effect of including $1.8 \mathrm{~g}$ EPA plus DHA per day (EPA/DHA capsules) as part of an ad libitum diet on body composition among 6 healthy young adults, substitution of fish oil for visible fats (butter, olive oil, sunflower oil, and peanut oil) significantly decreased body fat mass [18]. In that study, body fat mass was measured using dual-energy X-ray absorptiometry. Using precise measures of body fat mass may be important to detect an effect. Furthermore, that study showed that substitution of fish oil for visible fat increased basal fat oxidation, suggesting that long-chain n-3 PUFA may to some extent modulate the partitioning of fat between oxidation and deposition. However, a high dose of long-chain n-3 PUFA was used, and potential threshold effects were not investigated. In our study we found no consistent associations between the endogenous exposure to long-chain n-3 PUFA and subsequent change in body weight over the range of ex- posures observed in the general population. In a randomized trial the effect of including seafood or fish oil as part of an energy-restricted diet on weight loss among 278 young overweight or obese adults was investigated [19]. In that study, the inclusion of either lean fish (0.3 g long-chain n-3 PUFA per day), fatty fish (3.0 g long-chain n-3 PUFA per day), or fish oil capsules (1.5 g long-chain n-3 PUFA per day) resulted in more weight loss than did a control diet without marine food, but among men only. A specific effect of longchain n-3 PUFA may explain more weight loss of the diets including fatty fish or fish oil but not more weight loss of the diet including lean fish, as the content of long-chain n-3 PUFA was only slightly higher in the diet including lean fish than in the control diet. Thus, the findings from that study suggest that there are components of fish that may improve weight loss beyond long-chain n-3 PUFA.

The association between long-chain n-3 PUFA and body fat mass may depend on the size of the fat mass. The size of the fat mass measured as BMI was considered as a potential effect modifier in this study. Using BMI as a measure of fat mass size may rank the participants according to general obesity [20]. Sex and age were also considered as potential effect modifiers due to sex- and age-related differences in the size of the fat mass. The findings from this study, however, did not suggest systematical differences in the associations across strata of sex, age, or BMI.

In conclusion, the results of this study suggest that the proportion of long-chain n-3 PUFA in plasma phospholipids is not associated with subsequent change in body weight within the range of exposure in the general population. 


\section{Acknowledgements}

This work is part of the project Physical Activity, Nutrition, Alcohol, Cessation of Smoking, Eating out of Home and Obesity (PANACEA), which is supported by the European Union in the framework of the Public Health Programmme (Contract 2005328). The work was further supported by the European Commission: Public Health and Consumer Protection Directorate 1993-2004; Research Directorate-General 2005; Ligue contre le Cancer, Société 3M, Mutuelle Générale de l'Education Nationale, Institut National de la Santé de la Recherche Médicale (INSERM) (France); German Cancer Aid, German Cancer Research Center, Federal Ministry of Education and Research (Germany); Danish Cancer Society (Denmark); ISCIII (RETICC RD06/0020) of the Spanish Ministry of Health, the participating regional governments and institutions (Spain); Cancer Research UK, Medical Research Council, Stroke Association, British Heart Foundation, Department of Health, Food Standards Agency, The Wellcome Trust (UK); Greek Ministry of Health, Greek Ministry of Education, Hellenic Ministry of Health, Stavros Niarchos Foundation, and the Hellenic Health Foundation
(Greece); Italian Association for Research on Cancer, National Research Council (Italy); Dutch Ministry of Public Health, Welfare and Sports, Dutch Ministry of Health, Dutch Prevention Funds, LK Research Funds, Dutch Zorg Onderzoek Nederland (ZON), World Cancer Research Fund (WCRF) (The Netherlands); and Swedish Cancer Society, Swedish Scientific Council, Regional Government of Skane and Västerbotten (Sweden). This work is also part of the project Hepatic and Adipose Tissue and Functions in the Metabolic Syndrome (HEPADIP, www.hepadip.org), which is supported by the European Commission as an Integrated Project under the 6th Framework Programme (Contract LSHM-CT-2005-018734) and part of the research program of the Danish Obesity Research Centre (DanORC, www.danorc.dk), which is supported by the Danish Council for Strategic Research (Contract 2101-06-0005).

\section{Disclosure Statement}

The authors declare no conflict of interest.

\section{References}

1 Buckley JD, Howe PR: Anti-obesity effects of long-chain omega-3 polyunsaturated fatty acids. Obes Rev 2009;10:648-659.

2 Halkjaer J, Sorensen TI, Tjonneland A, Togo P, Holst C, Heitmann BL: Food and drinking patterns as predictors of 6-year BMI-adjusted changes in waist circumference. Br J Nutr 2004;92:735-748.

-3 Sun Q, Ma J, Campos H, Hankinson SE, Hu FB Comparison between plasma and erythrocyte fatty acid content as biomarkers of fatty acid intake in US women. Am J Clin Nutr 2007;86:74-81.

4 Hodson L, Skeaff CM, Fielding BA: Fatty acid composition of adipose tissue and blood in humans and its use as a biomarker of dietary intake. Prog Lipid Res 2008;47:348-380.

5 Karlsson M, Marild S, Brandberg J, Lonn L, Friberg P, Strandvik B: Serum phospholipid fatty acids, adipose tissue, and metabolic markers in obese adolescents. Obesity 2006;14:1931-1939.

6 Riboli E, Kaaks R: The EPIC Project: rationale and study design. European Prospective Investigation into Cancer and Nutrition. Int J Epidemiol 1997;26(suppl 1):S6-14.

7 Riboli E, Hunt KJ, Slimani N, Ferrari P, Norat T, Fahey M, Charrondiere UR, Hemon B, Casagrande C, Vignat J, Overvad K, Tjonneland A, ClavelChapelon F, Thiebaut A, Wahrendorf J, Boeing H, Trichopoulos D, Trichopoulou A, Vineis P, Palli D, Bueno-De-Mesquita HB, Peeters PH, Lund E, Engeset D, Gonzalez CA, Barricarte A, Berglund G, Hallmans G, Day NE, Key TJ, Kaaks R, Saracci R: European Prospective Investigation into Cancer and Nutrition (EPIC): study populations and data collection. Public Health Nutr 2002;5:1113-1124.
8 Saadatian-Elahi M, Slimani N, Chajes V, Jenab M, Goudable J, Biessy C, Ferrari P, Byrnes G, Autier P, Peeters PH, Ocke M, Bueno de MB, Johansson I, Hallmans G, Manjer J, Wirfalt E, Gonzalez CA, Navarro C, Martinez C, Amiano P, Suarez LR, Ardanaz E, Tjonneland A, Halkjaer J, Overvad K, Jakobsen MU, Berrino F, Pala V, Palli D, Tumino R, Vineis P, Santucci de MM, Spencer EA, Crowe FL, Bingham S, Khaw KT, Linseisen J, Rohrmann S, Boeing H, Noethlings U, Olsen KS, Skeie G, Lund E, Trichopoulou A, Oustoglou E, Clavel-Chapelon F, Riboli E: Plasma phospholipid fatty acid profiles and their association with food intakes: results from a cross-sectional study within the European Prospective Investigation into Cancer and Nutrition. Am J Clin Nutr 2009;89:331-346.

9 Haftenberger M, Lahmann PH, Panico S, Gonzalez CA, Seidell JC, Boeing H, Giurdanella MC, Krogh V, Bueno-De-Mesquita HB, Peeters PH, Skeie G, Hjartaker A, Rodriguez M, Quiros JR, Berglund G, Janlert U, Khaw KT, Spencer EA, Overvad $\mathrm{K}$, Tjonneland A, Clavel-Chapelon F, Tehard B, Miller AB, Klipstein-Grobusch K, Benetou V, Kiriazi G, Riboli E, Slimani N: Overweight, obesity and fat distribution in 50- to 64-year-old participants in the European Prospective Investigation into Cancer and Nutrition (EPIC). Public Health Nutr 2002;5:1147-1162.

10 de Groot LC, Sette S, Zajkas G, Carbajal A, Amorim JA: Nutritional status: anthropometry. Euronut SENECA investigators. Eur J Clin Nutr 1991;45(suppl 3):S31-42.

11 Spencer EA, Appleby PN, Davey GK, Key TJ: Validity of self-reported height and weight in 4808 EPIC-Oxford participants. Public Health Nutr 2002;5:561-565.

12 Day N, Oakes S, Luben R, Khaw KT, Bingham S, Welch A, Wareham N: EPIC-Norfolk: study design and characteristics of the cohort. European Prospective Investigation of Cancer. Br J Cancer 1999; 80(suppl 1):S95-103.
3 Wareham NJ, Jakes RW, Rennie KL, Schuit J, Mitchell J, Hennings S, Day NE: Validity and repeatability of a simple index derived from the short physical activity questionnaire used in the European Prospective Investigation into Cancer and Nutrition (EPIC) study. Public Health Nutr 2003;6: 407-413.

14 Arterburn LM, Hall EB, Oken H: Distribution, interconversion, and dose response of n-3 fatty acids in humans. Am J Clin Nutr 2006;83(suppl 6): S1467-1476.

15 Klein-Platat C, Drai J, Oujaa M, Schlienger JL, Simon C: Plasma fatty acid composition is associated with the metabolic syndrome and low-grade inflammation in overweight adolescents. Am J Clin Nutr 2005;82:1178-1184.

16 Micallef M, Munro I, Phang M, Garg M: Plasma $\mathrm{n}-3$ polyunsaturated fatty acids are negatively associated with obesity. Br J Nutr 2009;102:1370-1374.

17 Joensen AM, Schmidt EB, Dethlefsen C, Johnsen SP, Tjonneland A, Rasmussen LH, Overvad K Dietary intake of total marine $\mathrm{n}-3$ polyunsaturated fatty acids, eicosapentaenoic acid, docosahexaenoic acid and docosapentaenoic acid and the risk of acute coronary syndrome - a cohort study. Br J Nutr 2010;103:602-607.

18 Couet C, Delarue J, Ritz P, Antoine JM, Lamisse F: Effect of dietary fish oil on body fat mass and basal fat oxidation in healthy adults. Int $\mathrm{J}$ Obes 1997;21:637-643.

19 Thorsdottir I, Tomasson H, Gunnarsdottir I, Gisladottir E, Kiely M, Parra MD, Bandarra NM, Schaafsma G, Martinez JA: Randomized trial of weight-loss-diets for young adults varying in fish and fish oil content. Int J Obes 2007;31:1560-1566.

20 Janssen I, Heymsfield SB, Allison DB, Kotler DP, Ross R: Body mass index and waist circumference independently contribute to the prediction of nonabdominal, abdominal subcutaneous, and visceral fat. Am J Clin Nutr 2002;75:683-688. 